\title{
The Main Factors Affecting the Tendency for "Injection Drug Use”
}

\author{
Behrooz Hamzeh ${ }^{1}$, Farid Najafi ${ }^{2}$, Fatemeh Heydarpour ${ }^{1}$, Mehdi Moradinazar ${ }^{1}$ and Zeinab \\ Moradinazar ${ }^{3, *}$ \\ ${ }^{1}$ Research Center for Environmental Determinants of Health (RCEDH), Kermanshah University of Medical Sciences, School of Public Health, Kermanshah, IR Iran \\ ${ }^{2}$ Social Development and Health Promotion Research Center, Kermanshah University of Medical Sciences, Kermanshah, IR Iran \\ ${ }^{3}$ Kermanshah University of Medical Sciences, School of Public Health, Kermanshah, IR Iran \\ "Corresponding author: Zeinab Moradinazar, Research Center for Environmental Determinants of Health (RCEDH), Kermanshah University of Medical Sciences, School of \\ Public Health, Kermanshah, IR Iran, E-mail: zeinab.moradinazar@gmail.com
}

Received 2017 July 22; Revised 2018 March 04; Accepted 2018 March 11.

\begin{abstract}
Background: Injection drug use (IDU) is one of the most dangerous and addictive methods of drug abuse. The current statistics showed that the rate of IDU is increasing, and is higher compared to other methods of drugs abuse. In addition, it is one of the main routes of transmitting infectious diseases, such as human immunodeficiency virus (HIV) and hepatitis in Iran.

Objectives: In light of this, the present study aimed at examining the main factors, affecting the tendency for IDU.

Patients and Methods: This study was a descriptive study of 823 individuals, having an active file at centers and referred to Kermanshah-based maintenance methadone therapy (MMT) centers, in 2015. Sample collection was performed through multi-stage sampling of all MMT centers. Information gathering was performed with the help of a Psychologist of the ward, in charge of interviewing the referees. The data were analyzed, using multi-variable logistic regression.

Results: All the clients were males with an average age of $38.48 \pm 11.21$ years. Average age of drug abuse initiation was $23.03 \pm 7.9$ years. After controlling for confounding variables, the individuals, who were a drug addicts for more than 10 years had 3.01 (1.6 to 5.6) times greater tendencies for intravenous drug addiction, compared to those, who were a drug addict for less than five years. In addition, individuals aged more than 35 years had $0.06(0.01-0.22)$ times less tendencies to IDU drugs, compared to those, who were younger than 19 years old. Although the type of drug that the patient used for the first time, was not affecting the tendency, the risk of intravenous drug addiction in those, who used oral drugs was 1.74 (1.1 to 2.56) times more than those, who developed a drug addiction through nasal drugs.

Conclusions: By taking into consideration that drug abuse initiation and the duration of drug use were the main causes of the tendency for IDU, prevention by decreasing the age of the development of drug addiction and decreasing the duration of drug use, could be an effective measure to decrease the rate of IDU in the society.
\end{abstract}

Keywords: Addiction, Injection, Methadone

\section{Background}

Narcotic drug abuse is a serious issue at the international level, which has attracted attention of economic, social, political, and physiological experts (1). There are not many phenomena, like an addiction, that could trouble and threaten human societies (2). According to the $\mathrm{UN}$, there are 220 million drug addicts in the world, using heroin, opium, cocaine, crack cocaine, hashish, and crystal meth, every day (3). Developing countries are highly vulnerable to drug addiction and its consequences (4). Studies have shown that adolescence and early adulthood ages, are critical stages of life, featured with higher vulnerability to a variety of psychological diseases and drug abuse (5). Recently, the rate of drug addiction has surged, among the unemployed population and the method of use is shifting from smoking to intravenous injection (6). Prevalence of IDU is growing in the world and Iran. So that, as the latest statistics indicate, more than 200 million drug addicts around the world and $\mathbf{1 3 . 2}$ millions are using drugs intravenously (7).

Intravenous drug users (IDUs) are addicts with high risk of infections due to risky behaviors, such as using shared injection tools, tattoos, imprisonment, and the like. In most cases, the patients are not aware of their infection, and therefore, the infection spreads faster in the society (8, 9). Of the side effects of IDU, are infectious diseases, such as $\mathrm{HIV}, \mathrm{HBV}$, and $\mathrm{HCV}$, resulting in catastrophic problems due to higher prevalence of addiction in different social classes $(10,11)$. It is notable that high risk of infectious diseases is not limited to drug addicts, and also covers their sex part- 
ners, children, and other social groups $(12,13)$.

\section{Objectives}

With this introduction, the present study aimed to examine the risk factors for the tendency to IDU. The outcome might be a step forward towards codification and introduction of more efficient prevention programs.

\section{Patients and Methods}

\subsection{Study Population}

This cross-sectional (descriptive) study was carried out in Kermanshah province, located in the western region of Iran. This province is bordered by the Kurdistan province to the north, and Hamadan and Lorestan provinces to the east. It also has common borders with Iraq in the west. The total population of the province was estimated to be approximately two millions, in the year 2015.

The province has 95 methadone maintenance therapy (MMT) centers for the provision of services and quitting drugs. Among all the centers, 233 IDU subjects were enrolled in this study, and 590 clients as non-IDU were randomly selected, from 4,175 clients referred to the MMT centers.

In the MMT center, based on the ministry of health and medical education (MoHME) guidelines, all the required data were collected, through an interview with a psychologist, working full-time at the centers. The main inclusion criterion was treatment with methadone for at least one year. Demographics and information about the reasons for seeking treatment, previous attempts for stopping drug abuse, and the drug type, were collected from each participant. The economic situation of the individual, based on several measures, such as the financial situation of the addicts, house furniture, and living neighborhood, were taken into consideration, and accordingly, the subjects were categorized as having poor, average, and good conditions. Drug dependence was assessed based on Diagnostic and Statistical Manual of Mental Disorder (DSM-5). Drug abuse initiation, within the scope of this study, was the age of initiation of drug use.

\subsection{Data Analysis}

Descriptive statistics were used for describing the data, and data analysis was performed, using univariate and multi-variate logistic regression. Risk of IDU was computed as an odds ratio with a confidence level of $95 \%$. The final model in multi-variable logistic regression was selected as backward, so that the variable of a univariate model with a P value of $\leq 0.25$ was entered in the multivariable model and insignificant variables were removed. P values of $<0.05$ were considered statistically significant.

\section{Results}

All the clients were male with an average age of $38.48 \pm$ 11.21 years ( $37.43 \pm 11.21$ for IDU and $38.89 \pm 11.19$ for non-IDU). Frequency of clients based on marital status, indicated that frequency of IDU between the unmarried individuals was two times more than married individuals, and the difference in the IDU and non-IDU groups was significant $(\mathrm{P}<$ 0.001). The main drugs used by the clients were opium ( $\mathrm{n}$ $=573,69.7 \%)$, alcohol $(n=96,11.6 \%)$, amphetamine $(n=75$, $9.1 \%)$, psychedelic drugs $(n=46,5.6 \%)$, and sedatives $(n=33$, $4 \%$ ). The top reasons for initiation of drug abuse were seeking joy ( $\mathrm{n}=507,61.6 \%)$, curiosity and easy access to drugs $(\mathrm{n}=197,23.9 \%)$, having drug addicts among friends $(\mathrm{n}=69$, $8.4 \%)$, for medical purposes $(n=39,4.7 \%)$, and unemployment and economic problems $(\mathrm{n}=11,1.3 \%)$.

The age of initiation of drug abuse was the main preventive variable of IDU, so that the odds ratio of initiation of IDU in clients older than 35 was 0.06 (0.01 to 0.22) times more, compared to those younger than 19 years old (Table 1).

An increase in the duration of drug use increased the person's tendency to use drugs intravenously; so that in univariate and multi-variate models, a higher odds ratio of tendency to intravenous addiction was observed, in the individuals with more than 10 years of addiction, compared with people with less than five years of addiction. Controlling the confounding variables indicated that these individuals had 3.01 (1.6 to 5.6) times greater tendencies to develop an intravenous drug addiction, compared with individuals with less than five year of addiction (Table 1).

Drug abuse method adopted at initiation of drug abuse affected the tendency for IDU, so that individuals, who initiated drug abuse through oral use had 1.63 (1.16 to 2.27) times greater tendencies to IDU, compared with individuals, who had started with nasal methods.

In the univariate model, imprisonment experience was a preventive factor for initiation of IDU, with 0.37 ( 0.26 to 0.54 ) times less tendencies. However, controlling the confounding variable showed that the risk of IDU in individuals with imprisonment experience was 3.24 (2.11 to 4.99) times more, in comparison with those without imprisonment experience (Table 1 ).

\section{Discussion}

Addiction and the damaging outcome of drug abuse are widespread and complicated in nature, and all mem- 
bers of the society should feel responsibility, based on their power, in relation to this phenomenon. High prevalence of addiction among different age groups, wide variety of drugs and changes in drug use patterns in the recent years, have emerged as a serious social problem. A notable point in this regard is the increase of intravenous drug addiction and its side effects. Usually, addicts experience a higher level of joy and power, while injecting the drug and as a result, they continue to use drugs. The majority of intravenous drug addicts were using drugs before initiation of IDU and had shifted to intravenous use, due to developing resistance to the drug. Consequently, to experience the same level of joy and ecstasy, the addict needs to increase the dosage of the drug.

Initiation of drug abuse at younger age and high prevalence of addiction, among the youth is a serious warning alarm, for the society and officials. Adopting programs to prevent risky behaviors and decreasing damages, created in high-risk age groups, could be fruitful $(12,13)$.

Having drug addicts among one's friends was one of the key factors in development of intravenous drug addiction. This finding was consistent with a cohort study in North America, and a study in Germany (14). Tendency to socialize is a normal and natural behavior among the juvenile; however, this behavior has turned out to be risky, among individuals with lack of emotional support from their family, and with poor self-esteem. New members in juvenile social groups might be under pressure to do specific risky behaviors, to be accepted in the group. Only juveniles with high self-esteem can resist such pressure and create friendship with other individuals $(15,16)$.

Curiosity, easy access to narcotic drugs, unemployment and financial problems, tendency to experience joy, and false beliefs about painkilling effects of drugs, were the main factors, affecting the tendency for IDU. A study in Iran reported that curiosity and psychological problems were the main motivations for initiation of drug use (17). Easy access to drugs, adds to the risk of developing addiction, so that $75 \%$ to $98 \%$ of the juvenile with drug addiction, stated that they had easy access to drugs (18). As recommended by the current evidence, unemployment and financial problems are related to the tendency to intravenous drug addiction, which sounds reasonable, since drug addicts gradually lose their economic and professional positions (19, $20)$. Other factors, such as homelessness $(12,21,22)$, leaving school, and initiation of drug abuse at young ages were also affecting the tendency for IDU (23).

Consistent with a study in Kentucky, USA (24), the current results showed that people, who started with oral drug abuse had greater tendency towards IDU, compared with those, who started with smoking. In general, people start drug abuse through non-invasive methods, such as smoking, and eating, and as their body develops resistance to the drug, they shift to IDU to feel more joy and ecstasy. The results showed that the cost of drugs and a tendency to use them more efficiently were two effective factors, in determining the method of use of the drug. Non-intravenous methods are usually more costly (25).

In the current study, the average age of initiation of drug abuse was $23.03 \pm 7.9$ years, which was higher than reports by Day in Iran, and Pavarin in Italy (26). In addition, the findings indicated that tendency to IDU was lower, when the age of initiation of drug abuse was higher. Given that the Iranian population is young, there is an imperative need to focus on this age group in prevention programs.

The crimes that prisoners commit and are imprisoned for, are often the same high-risk behaviors that make them vulnerable to infectious diseases, such as AIDS and hepatitis. The prison environment, on the other hand, is the first opportunity for many, to get familiarized with bad behaviors, such as addiction, sexual abuse, and the like. Despite all controlling measures, risky behaviors, such as IDU, using a shared syringe, tattoos, and sexual intercourse are highly prevalent in prisons. Consistent with other studies in Iran $(27,28)$, the current results showed that imprisonment experience was one of the risk factors for tendency towards intravenous addiction. A study in Europe showed that $19 \%$ of drug addicts initiated drug use in prisons (29). Drug addicts in many countries, such as Canada, have access to sterilized syringes, though supervised injection sites in the society and in the prison (30). Experts believe that easy access to methadone can prevent risky behavior of IDU.

Consistent with other studies $(26,27)$, having a drug addict in the family, increases the risk of intravenous addiction in the rest of the family. This is a serious problem and creates emotional, spiritual, psychological, and behavioral problems among family members. A drug addict causes an abnormal neurological pressure for family members. Unexpected and frightening behaviors, normally seen among drug addicts, halts the normal life trend, in the family. Having drug-addicted parents increases the tendency towards addiction in the children, as they find drugs as the only way, to cope with their poor life conditions. The fear of addiction fades away in children with drug-addicted parents. In addition, drug-addicted parents are less caring and supportive towards their children, which can be an effective factor for child substance abuse.

Due to the lack of cooperation of the some participants, one limitation of this study was its failure to record the interviews. Therefore, the researchers explained the aim of the study to elevate their cooperation. 


\subsection{Conclusions}

Drug addiction is a high-risk subject, associated with dangerous and destructive behaviors due to cultural, economic, and social problems, with a sudden and strong urge for using drugs. High-density populations of drug addicts in prisons, based on domestic and foreign statistics, creates a focal point for development of dangerous infectious diseases, such as HIV and hepatitis. Dealing with the true causes of high prevalence of addiction, and improving health conditions in prisons must be a top priority in policies, adopted by the authorities.

\section{Footnotes}

Authors' Contribution: Behrooz Hamzeh and Dr Zeinab Moradinazar were involved in planning and implementation of the study, data collection, and contribution in drafting of the manuscript. Farid Najafi and Behrooz Hamzeh were involved in planning and implementation of the study, data collection, and contribution in drafting of the manuscript. All authors read and approved the final manuscript. Fatemeh Heydarpour revised the manuscript. Conflict of Interests: The authors had no conflicting interests to disclose.

Funding/Support: The project was supported by Kermanshah University of Medical Sciences (16900).

\section{References}

1. Boys A, Farrell M, Taylor C, Marsden J, Goodman R, Brugha T, et al. Psychiatric morbidity and substance use in young people aged 13-15 years: results from the Child and Adolescent Survey of Mental Health. Br J Psychiatry. 2003;182:509-17. [PubMed: 12777342].

2. Shargh A, Shakibi A, Nisary R, Alilo A. Survey of related factors with relapse of drug addiction in centers of drug addiction in Western Azarbaijan. J Uromieh Uni Med Sci. 2012;2:129-36.

3. Degenhardt L, Chiu WT, Sampson N, Kessler RC, Anthony JC, Angermeyer M, et al. Toward a global view of alcohol, tobacco, cannabis, and cocaine use: findings from the WHO World Mental Health Surveys. PLoSMed.2008;5(7). e141. doi:10.1371/journal.pmed.0050141.[PubMed: 18597549]. [PubMed Central: PMC2443200].

4. Aggleton P, Jenkins P, Malcolm A. HIV/AIDS and injecting drug use: Information, education and communication. Int J Drug Policy. 2005;16:21-30. doi:10.1016/j.drugpo.2005.02.006.

5. Delgadillo J, Gore S, Ali S, Ekers D, Gilbody S, Gilchrist G, et al. Feasibility randomized controlled trial of cognitive and behavioral interventions for depression symptoms in patients accessing drug and alcohol treatment. J Subst Abuse Treat. 2015;55:6-14. doi: 10.1016/j.jsat.2015.02.008. [PubMed: 25819701].

6. Sanchez JL, Todd CS, Bautista CT, Botros BA, Khakimov MM, Giyasova GM, et al. High HIV prevalence and risk factors among injection drug users in Tashkent, Uzbekistan, 2003-2004. Drug Alcohol Depend. 2006;82 Suppl 1:S15-22. [PubMed: 16769440].

7. Des Jarlais DC, Semaan S. HIV prevention for injecting drug users: the first 25 years and counting. Psychosom Med. 2008;70(5):606-11. doi: 10.1097/PSY.ob013e3181772157. [PubMed: 18519886].
8. Burattini M, Massad E, Rozman M, Azevedo R, Carvalho H. Correlation between HIV and HCV in Brazilian prisoners: evidence for parenteral transmission inside prison. Rev Saude Publica. 2000;34(5):4316. [PubMed: 11105105].

9. Cocozella DR, Albuquerque MM, Borzi S, Barrio M, Dascenzo V, Santecchia JC, et al. [Prevalence of hepatic involvement, alcoholism, hepatis $\mathrm{B}, \mathrm{C}$ and HIV in patients with background history of drug use].Acta Gastroenterol Latinoam. 2003;33(4):177-81. Spanish. [PubMed: 14708468].

10. Mojtahedzadeh V, Razani N, Malekinejad M, Vazirian M, Shoaee S, Saberi Zafarghandi MB, et al. Injection drug use in Rural Iran: integrating HIV prevention into iran's rural primary health care system. AIDS Behav. 2008;12(4 Suppl):S7-12. doi:10.1007/s10461-008-9408y. [PubMed: 18521737].

11. Todd CS, Abed AM, Strathdee SA, Scott PT, Botros BA, Safi N, et al. HIV, hepatitis $C$, and hepatitis B infections and associated risk behavior in injection drug users, Kabul, Afghanistan. Emerg Infect Dis 2007;13(9):1327-31. doi: 10.3201/eid1309.070036. [PubMed: 18252103]. [PubMed Central: PMC2857281].

12. Niknami SH, Hatami A, Heydarnia A. The effect of health educational program on preventing aids in self-reported addicts'wives (Kermanshah 2004). J Kermanshah Univ Med Sci. 2007;11(2).

13. Najarkolaei FR, Niknami S, Shokravi FA, Ahmadi F. Perception and behaviors of HIV/AIDS patients: a qualitative study. J Kermanshah Univ Med Sci. 2009;13(3)

14. Krumm-Merabet C, Meyer TD. Leisure activities, alcohol, and nicotine consumption in people with a hypomanic/hyperthymic temperament. Pers Individ Differ. 2005;38(3):701-12. doi: 10.1016/j.paid.2004.05.024

15. Aura A, Laatikainen T, Isoaho H, Lazutkina G, Tossavainen K. Adolescents' Attitudes on Smoking Are Related to Experimentation with Smoking, Daily Smoking and Best Friends' Smoking in Two Karelias in Finland and in Russia. Int J Behav Med. 2016;23(6):679-85. doi: 10.1007/s12529-016-9566-7. [PubMed: 27184970].

16. Somani S, Meghani S. Substance Abuse among Youth: A Harsh Reality. Emerg Med. 2016;6(4). doi: 10.4172/2165-7548.1000330.

17. Meymandi M, Ziaeddini H, Yazdi A. Opinion of high school students of Kerman towards affecting factors on narcotics tendency (2005). JQUMS. 2008;12:80-8

18. Khazaei H, Najafi F, Alavi Far A. Substance abuse prevalence and related factors to it, among students of Kermanshah University of Medical Science in 2011. J Kermanshah Univ Med Sci. 2013;17(3):197-205.

19. Neaigus A, Miller M, Friedman SR, Hagen DL, Sifaneck SJ, Ildefonso $G$, et al. Potential risk factors for the transition to injecting among non-injecting heroin users: a comparison of former injectors and never injectors. Addiction. 2001;96(6):847-60. doi: 10.1080/09652140020050960. [PubMed: 11399216].

20. Abelson J, Treloar C, Crawford J, Kippax S, van Beek I, Howard J. Some characteristics of early-onset injection drug users prior to and at the time of their first injection. Addiction. 2006;101(4):548-55. doi: 10.1111/j.1360-0443.2006.01379.x. [PubMed: 16548934].

21. Fischer B, Manzoni P, Rehm J. Comparing injecting and non-injecting illicit opioid users in a multisite Canadian sample (OPICAN Cohort). Eur Addict Res. 2006;12(4):230-9. doi: 10.1159/000094425. [PubMed 16968998].

22. Neaigus A, Gyarmathy VA, Miller M, Frajzyngier VM, Friedman SR, Des Jarlais DC. Transitions to injecting drug use among noninjecting heroin users: social network influence and individual susceptibility. J Acquir Immune Defic Syndr. 2006;41(4):493-503. doi: 10.1097/01.qai.0000186391.49205.3b. [PubMed:16652059].

23. Fuller CM, Vlahov D, Ompad DC, Shah N, Arria A, Strathdee SA. Highrisk behaviors associated with transition from illicit non-injection to injection drug use among adolescent and young adult drug users: a case-control study. Drug Alcohol Depend. 2002;66(2):189-98. [PubMed: $11906806]$. 
24. Young AM, Havens JR, Leukefeld CG. Route of administration for illicit prescription opioids: a comparison of rural and urban drug users. Harm Reduct J. 2010;7:24. doi: 10.1186/1477-7517-7-24. [PubMed: 20950455]. [PubMed Central: PMC2967505].

25. Strang J, Des Jarlais DC, Griffiths P, Gossop M. The study of transitions in the route of drug use: the route from one route to another. Br JAddict. 1992;87(3):473-83. [PubMed: 1559046].

26. Pavarin RM. Substance use and related problems: a study on the abuse of recreational and not recreational drugs in Northern Italy. Ann Ist Super Sanita. 2006;42(4):477-84. [PubMed: 17361073].

27. Shannon K, Ishida T, Morgan R, Bear A, Oleson M, Kerr T, et al. Potential community and public health impacts of medically supervised safer smoking facilities for crack cocaine users. Harm Reduct J 2006;3:1. doi: 10.1186/1477-7517-3-1. [PubMed: 16403229]. [PubMed Cen- tral: PMC1368973].

28. Tayeri K, Kasaeian N, Fadaei R, Ataei B. The prevalence of hepatitis B, hepatitis $C$ and associated risk factors in intravenous drug addicts (IVDA) with HIV in Isfahan. 2008.

29. Bird AG, Gore SM, Hutchinson SJ, Lewis SC, Cameron S, Burns S. Harm reduction measures and injecting inside prison versus mandatory drugs testing: results of a cross sectional anonymous questionnaire survey. The European Commission Network on HIV Infection and Hepatitis in Prison. BMJ. 1997;315(7099):21-4. [PubMed: 9233321]. [PubMed Central: PMC2127021].

30. Kerr T, Mitra S, Kennedy MC, McNeil R. Supervised injection facilities in Canada: past, present, and future. Harm Reduct J. 2017;14(1):28. doi: 10.1186/s12954-017-0154-1. [PubMed: 28521829]. [PubMed Central: PMC5437687]. 
Table 1. The Factors Effective on Tendency to IDU in the Univariate and Multivariate Model

\begin{tabular}{|c|c|c|c|}
\hline Variables & IDU/Total (\%) & Crude OR $(95 \% \mathrm{CI})$ & Adjusted OR(95\%CI) \\
\hline \multicolumn{4}{|l|}{ Age group, y } \\
\hline $20-29$ & $52 / 190(27.36)$ & & \\
\hline $30-39$ & $102 / 291(35.03)$ & $1.43(0.96-2.13)$ & \\
\hline $40-49$ & $44 / 203(21.67)$ & $10.73(0.46-1.16)$ & \\
\hline+50 & $35 / 139(25.17)$ & $0.89(0.54-1.47)$ & \\
\hline \multicolumn{4}{|l|}{ Education } \\
\hline Illiterate & $7 / 32(21.87)$ & 1 & \\
\hline Elementary & $48 / 172(27.90)$ & $1.38(0.56-3.40)$ & \\
\hline Guidance & $84 / 242(34.71)$ & $1.89(0.78-4.57)$ & \\
\hline Diploma & $64 / 267(23.97)$ & $1.12(0.46-2.72)$ & \\
\hline Academic & $30 / 110(27.00)$ & $1.33(0.52-3.41)$ & \\
\hline \multicolumn{4}{|l|}{ Marital } \\
\hline Unmarried & $119 / 257(46.30)$ & 1 & 1 \\
\hline Married & $79 / 503(15.70)$ & $0.21(0.15-0.30)$ & $0.23(0.16-0.33)$ \\
\hline Divorced & $35 / 63(55.56)$ & $1.44(0.83-2.52)$ & $1.56(0.88-2.78)$ \\
\hline \multicolumn{4}{|l|}{ Socioeconomic status } \\
\hline Well & $183 / 651(28.11)$ & 1 & \\
\hline Middle & $46 / 166(27.71)$ & $0.98(0.67-1.43)$ & \\
\hline Weak & $4 / 6(66.67)$ & $5.11(1.02-11.16)$ & \\
\hline \multicolumn{4}{|l|}{ Due to drug use } \\
\hline Seeking the joy & $126 / 507(24.85)$ & 1 & 1 \\
\hline Curiosity and easy access to drugs & $64 / 197(32.49)$ & $1.4(1.02-2.08)$ & $1.2(0.81-1.8)$ \\
\hline Having drug addicts among friends & $35 / 69(50.72)$ & $3.1(1.86-5.19)$ & $2.8(1.5-5.2)$ \\
\hline Seeking medical purposes & $5 / 39(12.82)$ & $0.44(0.17-1.16)$ & $0.56(0.19-1.6)$ \\
\hline Unemployment and economic problems & $3 / 11(27.27)$ & $1.13(0.29-4.33)$ & $1.6(0.28-9.5)$ \\
\hline \multicolumn{4}{|l|}{ Drug abuse method at first time } \\
\hline Nasal & $131 / 531(24.67)$ & 1 & 1 \\
\hline Oral & $80 / 230(34.78)$ & $1.63(1.16-2.27)$ & $1.8(1.2-2.8)$ \\
\hline Inhalation & $22 / 62(35.48)$ & $1.67(0.96-2.92)$ & $1.2(0.61-2.3)$ \\
\hline \multicolumn{4}{|l|}{ Drug abuse at first time } \\
\hline Opium & $145 / 573(25.3)$ & 1 & \\
\hline Alcohol & $27 / 96(28.1)$ & $1.1(0.72-1.8)$ & \\
\hline Amphetamine & $29 / 75(38.7)$ & $1.8(1.1-3.07)$ & \\
\hline Psychedelic drugs & $17 / 46(36.9)$ & $1.7(0.92-3.2)$ & \\
\hline Sedatives & $15 / 33(45.5)$ & $2.4(1.2-5.0)$ & \\
\hline \multicolumn{4}{|l|}{ Age of drug abuse initiation, $y$} \\
\hline$<19$ & $147 / 322(45.65)$ & 1 & 1 \\
\hline $20-24$ & $52 / 223(23.32)$ & $0.36(0.25-0.53)$ & $0.38(0.28-0.64)$ \\
\hline $25-29$ & $22 / 123(17.89)$ & $0.26(0.16-0.43)$ & $0.31(0.2-0.62)$ \\
\hline $30-34$ & 9/81(11.11) & $0.15(0.07-0.3)$ & $0.14(0.06-0.32)$ \\
\hline$\geq 35$ & $3 / 74(4.05)$ & $0.05(0.01-0.16)$ & $0.06(0.01-0.22)$ \\
\hline \multicolumn{4}{|l|}{ Drug dependence age, $y$} \\
\hline$<19$ & $64 / 226(28.32)$ & 1 & \\
\hline $20-24$ & $74 / 248(29.84)$ & $0.78(0.44-1.37)$ & \\
\hline $25-29$ & $35 / 132(26.52)$ & $0.66(0.35-1.24)$ & \\
\hline
\end{tabular}




\begin{tabular}{|c|c|c|c|}
\hline $30-34$ & $34 / 98(34.69)$ & $0.97(0.5-1.9)$ & \\
\hline$\geq 35$ & $26 / 119(21.85)$ & $0.51(0.26-0.99)$ & \\
\hline \multicolumn{4}{|c|}{ Addict in the family } \\
\hline No & $191 / 585(32.65)$ & 1 & 1 \\
\hline Yes & $42 / 238(17.65)$ & $2.26(1.6-3.3)$ & $0.30(0.20-0.48)$ \\
\hline \multicolumn{4}{|c|}{ Duration of drug use } \\
\hline$<5$ & $14 / 128(10.9)$ & 1 & 1 \\
\hline $5-10$ & $37 / 177(20.9)$ & $2.15(1.1-4.17)$ & $1.6(0.7-3.3)$ \\
\hline$>10$ & $182 / 518(35.1)$ & $4.4(2.4-7.9)$ & $3.01(1.6-5.6)$ \\
\hline \multicolumn{4}{|c|}{ Imprisonment experience } \\
\hline No & $167 / 681(24.52)$ & 1 & 1 \\
\hline Yes & $66 / 142(46.48)$ & $0.37(0.26-0.54)$ & $3.2(2.11-5.11)$ \\
\hline
\end{tabular}

